\title{
THE RISK TO STRUCTURES BUILT NEAR ROADS AND RAILS USED FOR MOVING HAZARDOUS MATERIALS
}

\author{
Egidijus Rytas VAIDOGAS, Lina KISEŽAUSKIENĖ, Ingrida GIRNIENE் \\ Department of Occupational Safety and Fire Protection, Faculty of Civil Engineering, \\ Vilnius Gediminas Technical University, Saulètekio al. 11, LT-10223 Vilnius, Lithuania
}

Received 26 Oct 2015; accepted 11 Nov 2015

\begin{abstract}
An assessment of parts of transportation infrastructure in terms of hazards to roadside territory is considered. It is suggested to assess individual segments of road and railway network by estimating risks posed by potential fires and explosions on road and rail. Boiling liquid expanding vapour explosion of tanker trucks and tank cars is identified as the most hazardous and likely high consequence accident in the land transport. It is proposed to express the risk to built roadside objects by means of an annual damage frequency. This frequency is considered to be a specific physical characteristic of the road or railway segment under analysis. It is shown that estimating the damage frequency requires assessing effects of a potential explosion on road or rail and developing a fragility function for the roadside object analysed as a potential target. An example case study is presented. It considers a potential thermal damage to a reservoir (stationary tank) built in the vicinity of a highway. The damage can be caused by an explosion of a propane tanker truck. Results of the risk assessment are expressed in terms of probabilities of specific damage events.
\end{abstract}

Keywords: road, railway, hazardous material, hydrocarbon, risk, accident, fire, explosion, BLEVE, damage.

\section{Introduction}

Safe transport of hazardous materials (hazmats) on land is a significant issue in each national economy. A large part of hazmats are moved by either trucks or trains. Hazards inherent in hazmats and previous accidents of hazmat transportation are cause of concern over a multi-faceted safety issue (Demir et al. 2015). The movement of hazmats poses risk to population stationed in the vicinity of roads and railways, environment of the areas near transportation routes and property built close to these routes (e.g. Qiu et al. 2015).

Most of the work devoted to a transportation risk assessment deals with risk to people and environment (e.g. Høj, Kröger 2002; Saat et al. 2014). The risk related to potential damage to build roadside objects (objects located near roads and railways) was considered only episodically, not in a systematic way. This can be explained in part by the simple fact that buildings and stationary equipment of industrial facilities are less vulnerable to effects of hazmat transportation accidents than people and natural environment. In addition, many accidents occur as toxic releases. They do not endanger built property. Major fires and explosions on road and rail are comparatively rare phenomena. However, damage caused by them can cover vulnerable roadside targets of all kinds: people, environment and built property. Relatively recent exam- ples of such events were disasters caused by derailments of freight trains in the Italian town Viareggio (Toscana, Italy, 2009, 31 person killed) and Canadian town Lac-Mégantic (Quebec, Canada, 2013, 47 persons killed) (Landucci et al. 2011; Dekker 2014). Damaging phenomena of these accidents were fires and explosions of hydrocarbons released from tank cars. Numerous buildings were damaged or destroyed in these accidents. Both accidents affected transportation safety policies in European Union and Canada.

As in the case with the risk to people and environment, the natural format suitable for estimating the risk to built roadside objects is a probabilistic risk assessment (PRA). The prime objective of this study was to highlight the role and possibilities of structural analysis in the process of PRA. In terms of Eurocodes, such an analysis will serve the purpose of structural design for accidental design situations (e.g. Vaidogas 2007a, 2007b; Vaidogas, Linkute 2012). A new procedure is suggested to relate individual hazmat moved by truck or train to specific thermal and/or mechanical damages to a roadside object. The basic idea of the procedure is to split the process of PRA into two tasks: predicting actions induced by fires and explosions and developing fragility functions for individual damage events. Mathematical models of actions and fragility functions are then applied in combination 
to an estimation of damage probabilities by means of a stochastic (Monte Carlo) simulation.

The variety of hazmats, which can be involved in fires and explosions of trucks and trains, is relatively large. Some hazmats can cause accidents of different types. For instance, liquefied flammable gas can trigger off flash fire or vapour cloud explosion or can be the cause of a catastrophic thermally induced rupture of a pressurised tanker vessel. The latter accident is known as a boiling liquid expanding vapour explosion (BLEVE). In order to keep our discussion within limits of one article, the further talk will be focussed mainly on BLEVEs. An example case study presented in the third section deals with thermal damage due to radiation emitted by a BLEVE fireball. This study is aimed at improving the situation with assessing the existing safety along transportation routes, providing sufficient separation distances between transportation routes and vulnerable roadside objects and designing structures which can sustain fires and explosions occurring on road and rail. In a broader sense, findings of the present study can be applied to planning urban and industrial territories and ensuring safety of inhabited areas along transportation routes. The findings can also be used for a safety-related decision-making based on formal operation research methods (e.g. Vaidogas, Šakénaitė 2010, 2011).

\section{Main transportation hazards to the infrastruc- ture built in the roadside territory}

\subsection{Accidents capable to damage roadside property}

Releases of toxic liquids or gases and subsequent atmospheric dispersions of toxic clouds can cause damaging effects to environment and population located working in the vicinity of roads. Fires and explosions pose the hazard of thermal and mechanical actions which can severely damage built property in the roadside territory. The frequency of fires and explosions and so the likelihood of these events in the future can be assessed by applying such databases as the Hazardous Materials Incident Reporting System (HMIRS) run by the US Department of Transportation (PHMSA 2014; Ronza et al. 2007). The HMIRS database is public and available online.

Table 1 contains counts of hazmat transportation accidents and incidents in the 10-year period 2003-2012 on US roads and railways. The numbers of fires and explosions among these events are presented in separate columns. These numbers are relatively small as compared to the total number of events reported to HMIRS. However, HMIRS contains a very large number of incidents which caused little of no damage. Such incidents are mainly small spills and evaporations. Another obvious conclusion which follows from Table 1 is that hazmat transportation by rail causes a substantially smaller number of accidents and incidents than moving such materials by trucks. This conclusion is confirmed also by other authors (e.g. Spraggings 2010).
Table 1. Numbers of fires and explosions in hazmat transportation accidents on US roads and railways in the 11-year period 2003 to 2013 (extracted from the HMIRS database (PHMSA 2014))

\begin{tabular}{c|c|c|c|c|c|c}
\hline \multirow{2}{*}{ Year } & \multicolumn{2}{|c}{$\begin{array}{c}\text { Total number of } \\
\text { reported accidents }\end{array}$} & \multicolumn{2}{c}{$\begin{array}{c}\text { Number of } \\
\text { fires }\end{array}$} & \multicolumn{2}{c}{$\begin{array}{c}\text { Number of } \\
\text { explosions }\end{array}$} \\
\cline { 2 - 7 } & Road & Rail & Road & Rail & Road & Rail \\
\hline 2003 & 13594 & 802 & 40 & 4 & 26 & 1 \\
2004 & 13068 & 765 & 49 & 3 & 24 & 0 \\
2005 & 13460 & 745 & 29 & 2 & 56 & 1 \\
2006 & 17159 & 703 & 30 & 2 & 49 & 0 \\
2007 & 16932 & 753 & 43 & 6 & 60 & 2 \\
2008 & 14802 & 748 & 48 & 4 & 46 & 0 \\
2009 & 12730 & 642 & 46 & 2 & 24 & 0 \\
2010 & 12652 & 749 & 49 & 3 & 47 & 0 \\
2011 & 13237 & 745 & 32 & 2 & 16 & 2 \\
2012 & 13249 & 662 & 63 & 6 & 13 & 1 \\
2013 & 13728 & 665 & 49 & 2 & 14 & 2 \\
\hline Total: & 154611 & 7979 & 478 & 36 & 375 & 9 \\
\hline
\end{tabular}

The HMIRS database was searched for hazardous materials which most often are involved in transportation accidents. These materials are commercial energetic hydrocarbons (LNG; LPG; light fractions including petrol and naphtha, crude oil; kerosene and jet fuel; diesel fuel; gas oil and No. 1 and 2 fuel oil; No. 4, 5, 6 fuel oils) (Ronza et al. 2007).

In Lithuania, large amounts of commercial hydrocarbons are shipped every day by road and rail to ensure a distribution to end-consumers. These materials are the main type of hazmats in the Lithuanian transportation network (Baublys 2003). The increasing consumption of hydrocarbons in Europe and construction of new gas terminals along the eastern shores of Baltic Sea may drive up transportation of hydrocarbons by road in the Baltic States (Kavalov et al. 2007).

Traffic accidents of trucks and trains shipping commercial hydrocarbons pose serious risk to built infrastructure located in the vicinity of roads and railways (e.g. Oggero et al. 2006). These accidents can escalate into fires and explosions which are able to cause thermal and/ or mechanical damage to roadside objects. The main types of fires and explosions on road and rail are common to transportation, fuelling, loading and unloading activities worldwide (e.g. Casal 2008; Quest Consultants 2009): pool fire (fire of a pool of combustible liquid resulting from a leak from a tanker vessel); jet fire (combustion of flammable gas or vapour released at a certain velocity through a hole in a pressurised tanker vessel); flash fire (a quick combustion of a cloud formed by a flash vaporisation of a flammable liquid or by evaporation of a pool of such liquid); vapour cloud explosion (VCE, a release of a flammable vapour from a tanker vessel followed by formation, ignition and high-speed combustion of a flammable cloud; such combustion can produce a significant blast overpressure); and BLEVE. 
Thermal effects of pool fire, jet fires and flash fires will be limited by a relatively small amount of flammable liquids and gases which are typically carried by road and railway tankers. The flash fire due to release of LPG from a car tank in Viareggio caused substantially smaller damage than the VCE triggered off by a release of caprolactanum in a fixed installation of Flixborough factory (UK, 1974). However, the fires mentioned above can cause secondary, "knock-on" accidents, such as a BLEVE (Hemmatian et al. 2015; Spoelstra et al. 2015).

VCEs have a large potential of widespread mechanical damage to roadside property. However, most VCEs occurred in fixed industrial facilities. Lenoir and Davenport (1993) listed 103 suspected VCE accidents that produced observable overpressures during the period 1921-1991. Of these events, only 10\% were rail car and road tanker accidents and 7\% waterway vessel accidents. Consequently, one can state that land transportation of commercial hydrocarbons is not too much prone to VCE accidents. However, some VCE accidents in transportation caused major damage to built property. An often cited example was a VCE cause by a puncture of an LPG tank car in East St. Louis (USA) on January 22, 1972 (Eichler, Napadentsky 1977).

Another accidental phenomenon which can be extremely hazardous to roadside territory is BLEVE (Abbasi, T., Abbasi, S. A. 2007; Eckhoff 2014). The immediate effects of BLEVE are blast and projectiles. If the commodity in a tank vessel sustaining BLEVE is flammable and is ignited immediately then a fireball is possible with the associated hazards of fire engulfment and thermal radiation. If the flammable commodity is not ignited immediately, then delayed ignition may lead to widespread fires or, in some cases, explosions (Birk 1996).

\subsection{Hazardous materials involved in BLEVEs of road and railway tankers}

Short reviews of accidents involving BLEVEs in transportation are presented by T. Abbassi and S. A. Abbassi (2007) and Tauseef et al. (2010). Planas-Cuchi et al. (2004), Bonilla Martinez et al. (2012) and Planas et al. (2015) described in detail two BLEVEs of road tankers which occurred in Spain in 2002 and 2011. However, neither of these publications attempted to systematise information on a greater or lesser number of BLEVEs in transportation in terms of, say, types commodities involved in accidents or damage to roadside property.

A relatively informative source of world-wide data on BLEVEs in transportation is the "hazardous materials knowledge base" known also as "failure and accidents technical information system" or, in brief, FACTS (FACTS 2014). It allows identifying hazmats involved in BLEVE accidents on road and rail. Figure 1 presents information extracted from FACTS on 43 BLEVE accidents, which occurred on road, and 38 BLEVEs, in which railway cars were involved. Although these accidents present only a relatively small fraction of BLEVEs in transportation, an analysis of them allows making three conclusions:

1. The hazmat, which was most frequently involved in BLEVEs on road and rail, is LPG;

2. Most BLEVEs of road and railway tankers occurred on open roads and railways, that is, not inside or in the vicinity of build-up and industrialised areas;

3. The prevailing locations of BLEVE in the railway transportation network were railways (21 cases) and low-speed motion areas (rail yards and railway stations, 7 cases). The exposure of built objects to BLEVE effects is higher in the latter areas than in sparsely built areas along railways. (a)

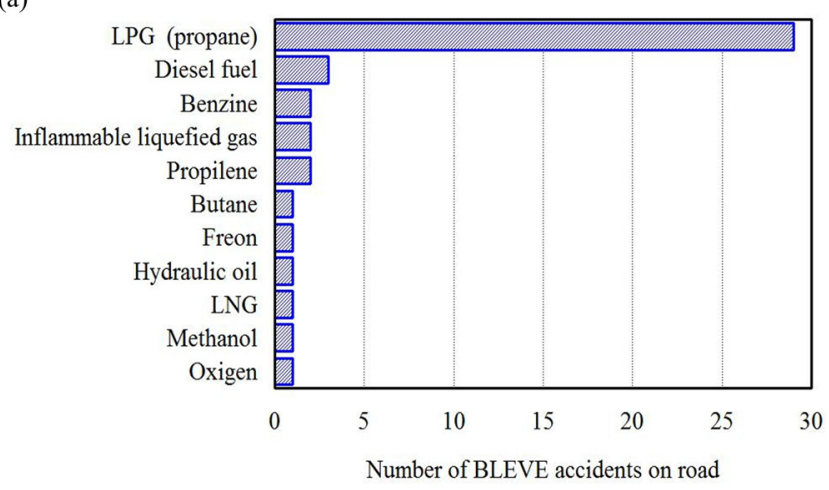

(b)

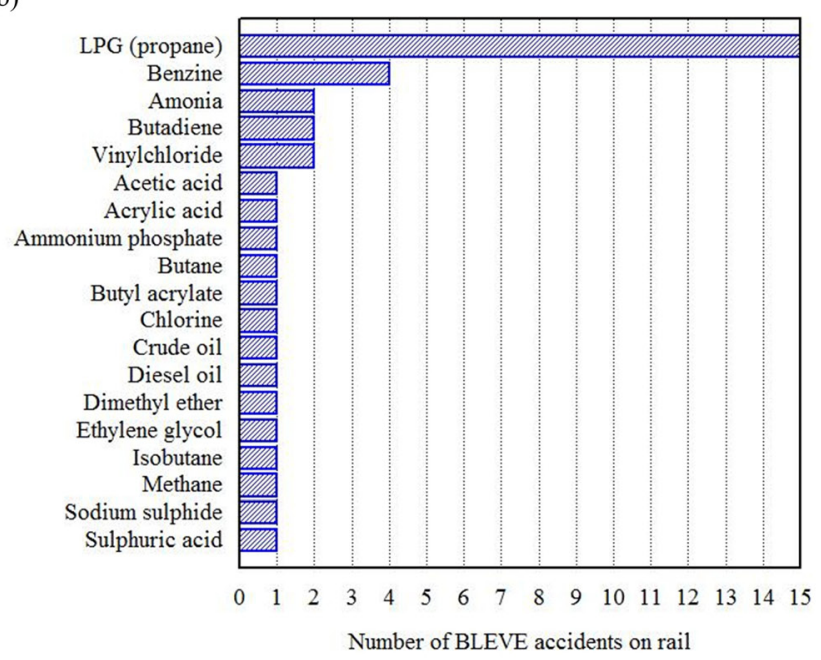

Fig. 1. Hazardous materials transported by road and railway tankers and involved in BLEVE accidents: (a) data on 43 accidents on road; (b) data on 38 BLEVE accidents on rail (extracted from the FACTS database (FACTS 2014)) 


\subsection{VCE and BLEVE on road and rail: a comparison of hazards}

VCEs in transportation are less frequent than BLEVEs. A formation of a vapour cloud with flammable concentration and movement of this cloud towards a potential target in the roadside territory requires an existence of specific meteorological conditions (e.g. CCPS 1994). In addition, the cloud must meet an ignition source. Such source will not necessarily be present and the cloud can simply disperse in the air. A supersonic propagation of the flame in the cloud (a detonation) will be possible if the concentration of the cloud will be fairly uniform throughout its volume. Otherwise, the flame will propagate at subsonic speed (VCE will occur as a deflagration) and overpressure will be modest as compared to devastating overpressures generated by the detonation. Finally, the combustion of the cloud can occur as a flash fire with negligible overpressure. Consequently, the chance that a flammable spill from a road or railway tanker will escalate into a VCE, which occurs as a detonation, is relatively small (Ronza et al. 2007; Chang, Tsai 2015).

A "hot" BLEVE of a road or railway tanker can be induced by external heating of a tanker vessel followed by catastrophic failure of the tank and explosive release of boiling liquid and expanding vapour. A "cold" BLEVE can occur without external fire, namely, due to an instantaneous rupture of the tank with immediate release of its contents. BLEVEs of this type are caused by impact in a collision or derailment or material defects. In road transport, $50 \%$ of the cases are "cold" BLEVEs and $50 \%$ of the cases are "hot" BLEVEs. As regards the rail transport, roughly $70-80 \%$ of BLEVEs are "hot" ones (TNO 2005). We think that the number of possibilities for BLEVE to occur on road or rail is larger than the number of possibilities of a detonation of a vapour cloud formed by a flammable release from a tanker.

Any comprehensive study which compares in detail the risks posed by VCEs and BLEVEs on road or rail is not known to us. We were able to find only a relatively small number of transportation-related publications which consider occurrences of VCEs and BLEVEs independently of one another. However, we feel intuitively that the land transportation network is more prone to BLEVEs than to VCEs occurring as detonations. In addition, the effects of BLEVEs are ternary (a relatively moderate blast, thermal radiation and projectile impact), whereas VCEs will generate only blast which is more likely to occur as a deflagration than as a detonation. In order to limit the amount of our study, we decided to deal with the BLEVEs only.

\section{Formal expression of risk to a roadside object stemming form a potential accident on road or rail}

\subsection{Likelihood of damage events}

In terms of PRA, such an explosion as BLEVE belongs to a sequence of adverse events which make up one of possible accident scenarios. This sequence usually starts with a traffic accident in which a road or railway tanker prone to sustain BLEVE is involved. In the worst case, the traffic accident will escalate into an explosion of the tanker. Effects of this explosion (thermal radiation from a BLEVE fireball, blast and fragments of a tanker vessel) will go far outside the road or railway and may be capable to damage objects built in the vicinity of them. Fragments are the furthest reaching effect of BLEVE (e.g. Birk 1996). An individual vulnerable roadside object (a reservoir, say) can sustain several damages of different type. An occurrence of these damages given a BLEVE is uncertain and therefore they can be represented by a set of random events $\mathcal{D}_{d}\left(d=1,2, \ldots, n_{d}\right)$, where $n_{d}$ is the number of identifiable damages. Examples of $\mathcal{D}_{d}$ can be loss of containment of a reservoir due to local or global failure, initiation of fire, rupture of a pipeline or other energy line. An occurrence of at least one of $\mathcal{D}_{d}$ given a BLEVE event $\mathcal{B}$, can be expressed by the union:

$$
\mathcal{D}=\bigcup_{d=1}^{n_{d}} \mathcal{D}_{d}
$$

where $\mathcal{D}$ denotes the random event representing any damage or combination of damages resulting from a BLEVE. In the simple case where the events $\mathcal{D}_{d}$ are mutually exclusive, the risk posed by a BLEVE to a roadside object can be defined as:

$$
\text { Risk }=\left\{\left(L\left(\mathcal{D}_{d}\right), \mathrm{S}_{d}\right), d=1,2, \ldots, n_{d}\right\},
$$

where $L\left(\mathcal{D}_{d}\right)$ is the likelihood of $\mathcal{D}_{d}$ expressed usually as an annual damage frequency and $\boldsymbol{S}_{d}$ is the vector containing measures of magnitude (severity) of the events $\mathcal{D}_{d}$ (e.g. Kumamoto 2007). The magnitude of $\mathcal{D}_{d}$ will depend on whether $\mathcal{D}_{d}$ represents a stand-alone event or alternatively an event which triggers off a domino sequence. If some of the events $\mathcal{D}_{d}$ are not mutually exclusive, the set defined by Eqn (2) should be supplemented by members expressing likelihoods and magnitudes of intersections of those events $\mathcal{D}_{d}$ which can occur simultaneously. For instance, a structural roadside object can be ignited by a thermal radiation from a BLEVE fireball and at the same time it can sustain local or global mechanical damage due to a fragment impact.

In a broader context of PRA applied to industrial facilities, a road tanker BLEVE should be considered as an external or internal initiating event depending on where it can occur (e.g. IAEA 2003). The expression of risk will reflect all identifiable scenarios of accidents which can be triggered off by this BLEVE. However, the present study will be focussed to an assessment of damage to a specific roadside object. Therefore the subsequent analysis will be based on the structurally-oriented, "narrow" definition of risk given by Eqn (2). The attention will be cantered on an estimation of the likelihoods $L\left(\mathcal{D}_{d}\right)$. They can be decomposed as follows:

$$
L\left(\mathcal{D}_{d}\right)=F(\mathcal{M}) P(\mathcal{A} \mid \mathcal{M}) P(\mathcal{B} \mid \mathcal{A}) P\left(\mathcal{D}_{d} \mid \mathcal{B}\right),
$$


where $F(\mathcal{M})$ is the frequency of mission (random event $\mathcal{M}$ ) of moving hazardous cargo along a potential roadside target; $P(\mathcal{A} \mid \mathcal{M})$ is the conditional probability of a traffic accident (random event $\mathcal{A}$ ) given $\mathcal{M} ; P(\mathcal{B} \mid \mathcal{A})$ is the conditional probability that the traffic accident will escalate into a BLEVE (random event $\mathcal{B}$ ) and $P\left(\mathcal{D}_{d} \mid \mathcal{B}\right)$ is the conditional probability of the damage event $\mathcal{D}_{d}$ given $\mathcal{B}$.

\subsection{Probabilities of damage from a BLEVE}

An estimation of the conditional damage probabilities $P\left(\mathcal{D}_{d} \mid \mathcal{B}\right)$ will require assessing an exposed roadside object for three effects of BLEVE: blast, impact by tanker vessel fragments (projectiles) and thermal radiation from a BLEVE fireball. The possibilities to estimate $P\left(\mathcal{D}_{d} \mid \mathcal{B}\right)$ will depend on physical nature of these effects and availability of mathematical models allowing predicting their intensity and interaction with the exposed object.

The literature on blast from BLEVEs states in general that blast overpressure is localised and not significant at larger distances (e.g. Birk 1996). The blast does not reach as far as thermal radiation and fragment effects. In addition, the production of the overpressure is still not well understood and so accurate models aimed at an assessment of the overpressure are under development until now (Laboureur et al. 2015).

If the event $\mathcal{D}_{d}$ represents damage due to a fragment impact, the probability $P\left(\mathcal{D}_{d} \mid \mathcal{B}\right)$ can be decomposed as follows:

$$
P\left(\mathcal{D}_{d} \mid \mathcal{B}\right)=P(\mathcal{H} \mid \mathcal{B}) P\left(\mathcal{D}_{d} \mid \mathcal{H}\right)
$$

where $P(\mathcal{H} \mid \mathcal{B})$ is the probability that a fragment generated by a BLEVE will collide with the exposed object (the random collision event $\mathcal{H}$ will occur) and $P\left(\mathcal{D}_{d} \mid \mathcal{H}\right)$ is the probability that the fragment will cause the damage $\mathcal{D}_{d}$ given $\mathcal{H}$. The probability $P(\mathcal{H} \mid \mathcal{B})$ is estimated with relative ease by applying a stochastic simulation of vessel fragmentation and flights of fragments (Mébarki et al. 2009, 2012; Pula et al. 2007; Lisi et al. 2015; Sun et al. 2015).

The situation is different with an estimation of the probability $P\left(\mathcal{D}_{d} \mid \mathcal{H}\right)$. There is a substantial body of literature on experimental studies and mathematical modelling of low-speed and high-speed projectile impact. However, most studies deal with model development for impact effects of "hard" projectiles (e.g. Morinière et al. 2014; Anderson, Riegel 2015; Coffield, Adeli 2014). The deformability of such projectiles is small in comparison to the target deformability. In addition, these projectiles are usually small with respect to buildings and most of open-air industrial equipment. Projectiles ejected by a BLEVE of a tanker vessel will be large and relatively deformable vessel fragments, mainly end-caps and oblong end-caps of the vessel (Planas-Cuchi et al. 2004; Planas et al. 2015). They can be classified as "soft" ones and may collide with the target at different angles of in- cidence and different spatial orientation with respect to the target. Experimental investigations and modelling the effects of such "soft" impact are still in progress (e.g. $\mathrm{Xu}$ et al. 2015). To the best of our knowledge, accurate mathematical models of "soft" impact effects and interaction of large "soft" projectiles with targets of different mechanical nature are still to be developed. This makes a more or less realistic estimation of the conditional probabilities $P\left(\mathcal{D}_{d} \mid \mathcal{H}\right)$ problematic, particularly when projectile-target interaction and/or mechanical nature of the da mage event $\mathcal{D}_{d}$ are complicated. At present, a practicable approach to assessing risk of a potential fragment impact is to replace the likelihoods $L\left(\mathcal{D}_{d}\right)$ by the likelihood $L(\mathcal{H}) \propto P(\mathcal{H} \mid \mathcal{B})$ and control this risk on the basis of latter value.

The thermal radiation can ignite combustible parts of the exposed object and so the damage will be caused by a subsequent, secondary fire. Many combustible materials ignite at 10 second exposure to $50 \mathrm{~kW} / \mathrm{m}^{2}$ radiation (Prugh 1994). The duration of a fireball generated by a BLEVE of a typical road or railway tank is up to 20 seconds. Blast and projectiles will reach the target object within first two or three seconds after the explosion and act a very short time. Thermal radiation from a fireball will act on the object a longer time. If the events of mechanical and thermal damage are modelled by the respective random events $\mathcal{D}_{M} \equiv \mathcal{D}_{1}$ and $\mathcal{D}_{T} \equiv \mathcal{D}_{2}$, the event $\mathcal{D}_{M}$ will occur first and $\mathcal{D}_{T}$ will follow $\mathcal{D}_{M}$.

An occurrence of the mechanical damage event $\mathcal{D}_{M}$ can lead to two conditions of the target object with respect to the vulnerability of this object to thermal radiation:

1. An occurrence of $\mathcal{D}_{M}$ does not change the vulnerability to fire damage (e.g. a local damage to a masonry wall of an industrial building hit by a projectile from a tanker vessel fragmentation will not affect the vulnerability of its roof to thermal radiation, Figure 2(a)). The events $\mathcal{D}_{M}$ and $\mathcal{D}_{T}$ can be considered independent and so the probability $P\left(\mathcal{D}_{T} \mid \mathcal{B}\right)$ estimated independently from $P\left(\mathcal{D}_{M} \mid \mathcal{B}\right)$;

2. An occurrence of $\mathcal{D}_{M}$ increases abruptly the vulnerability to fire damage (e.g. loss of containment by a reservoir used to store flammable liquid due to a projectile impact and so spill and exposure of this liquid to the direct action of thermal radiation will increase the chance of fire, Figure 2(b)). The events $\mathcal{D}_{M}$ and $\mathcal{D}_{T}$ can not be considered to be independent and so $P\left(\mathcal{D}_{T} \mid \mathcal{D}_{M} \cap \mathcal{B}\right)>P\left(\mathcal{D}_{T} \mid \mathcal{B}\right)$.

The probabilities $P\left(\mathcal{D}_{T} \mid \mathcal{B}\right)$ and $P\left(\mathcal{D}_{T} \mid \mathcal{D}_{M} \cap \mathcal{B}\right)$ represent two different accident scenarios. An estimation of the conditional thermal damage probability $P\left(\mathcal{D}_{T} \mid \mathcal{B}\right)$ is similar to that of $P\left(\mathcal{D}_{T} \mid \mathcal{D}_{M} \cap \mathcal{B}\right)$, with the difference that the first probability must be estimated for a mechanically undamaged target object and the second one for an object in a damaged state and so more vulnerable to a thermal impact. Due to this similarity and for the sake of brevity, the symbol $P\left(\mathcal{D}_{T} \mid \mathcal{B}\right)$ in what follows will represent both probabilities. 
(a)

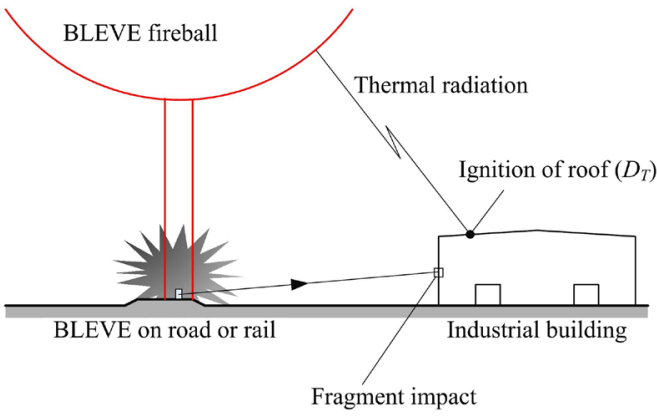

(b)

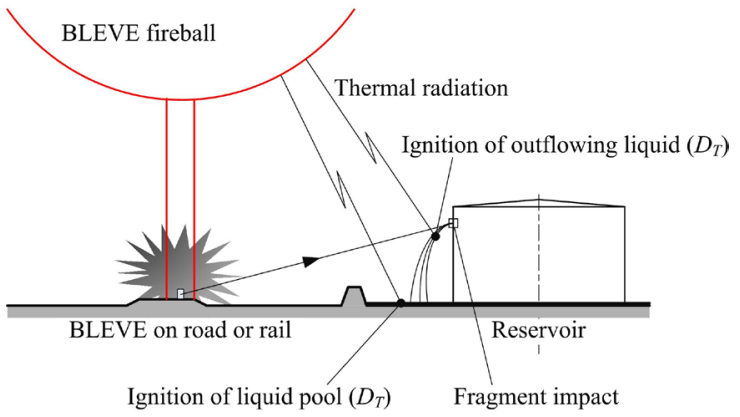

Fig. 2. An illustration of the thermal damage event $\mathcal{D}_{T}$ : (a) the case of an independent occurrence of $\mathcal{D}_{T}$ with respect to the mechanical damage by a projectile (event $\mathcal{D}_{M}$ ); (b) the case where $\mathcal{D}_{T}$ (ignition of flammable liquid) is dependent on an occurrence of mechanical damage (event $\mathcal{D}_{M}$ occurring as a perforation of a reservoir wall by a projectile and subsequent leak of liquid)

\subsection{Vulnerability of roadside object to thermal damage}

The thermal damage probability $P\left(\mathcal{D}_{T} \mid \mathcal{B}\right)$ can be expressed as follows (e.g. Vaidogas 2007a, 2007b):

$$
\begin{aligned}
P\left(\mathcal{D}_{T} \mid \mathcal{B}\right)= & \int_{\text {all } \boldsymbol{y}} P\left(\mathcal{D}_{T} \mid \boldsymbol{y}\right) f(\boldsymbol{y}) \mathrm{d} \boldsymbol{y}= \\
& \int_{\text {all } \boldsymbol{x}} P\left(\mathcal{D}_{T} \mid \boldsymbol{\psi}(\boldsymbol{x})\right) f(\boldsymbol{x}) \mathrm{d} \boldsymbol{x},
\end{aligned}
$$

where $\boldsymbol{y}=\left(y_{1}, y_{2}\right)$ is a two-component vector, the first component of which, $y_{1}$, expresses a thermal radiation intensity (heat flux) and the second, $y_{2}$, the duration of exposure to this radiation (fireball duration); $P\left(\mathcal{D}_{T} \mid \boldsymbol{y}\right)$ is the fragility function relating the probability of $\mathcal{D}_{T}$ to $\boldsymbol{y} ; \boldsymbol{x}$ is the vector of characteristics of BLEVE accident resulting in the impact expressed by $\boldsymbol{y} ; \boldsymbol{\psi}(\boldsymbol{x})$ is the vector-function which relates $\boldsymbol{x}$ to $\boldsymbol{y}$ (i.e., $\boldsymbol{y}=\boldsymbol{\psi}(\boldsymbol{x})$ ); and $f(\boldsymbol{x})$ and $f(\boldsymbol{y})$ are the joint probability density functions (p.d.f.s) of $\boldsymbol{x}$ and $\boldsymbol{y}$, respectively.

A development of the fragility function $P\left(\mathcal{D}_{T} \mid \boldsymbol{y}\right)$ is a highly case-specific task of probabilistic structural analysis. Fragility functions are widely applied to seismic risk assessment and extreme-wind risk assessment. However, any attempts to develop a fragility function for thermal actions of external fires are not known to us. We can only mention an attempt made by Vaidogas and Juocevičius (2008) to develop a fragility function for a timber structure exposed to an enclosure (internal) fire.

Recipes allowing relating the thermal radiation $y_{1}$ and fireball duration $y_{2}$ to a specific thermal damage are very sparse and deterministic in nature. It is stated in the books CCPS (1994) and CPD (2005) that the radiation of $37.5 \mathrm{~kW} / \mathrm{m}^{2}$ is sufficient to cause damage to process equipment and $12.5 \mathrm{~kW} / \mathrm{m}^{2}$ is the minimum energy required for ignition of wood and melting of plastic tubing.

Most sources interpret the thermal damage simply as an ignition of materials exposed to thermal radiation and distinguish between ignition and non-ignition by specifying a pair of fixed threshold values $\left(y_{1, \min }, y_{2, \min }\right)$ (e.g. Tewarson 2002; Babrauskas 2003). Unfortunately, such values are insufficient to easily develop a fragility function $P\left(\mathcal{D}_{T} \mid y_{1}, y_{2}\right)$, especially for short-term exposures (values of $y_{2}$ ranging roughly between 5 and 20 seconds). It is highly probable that at present the analyst will have to rely on a simplified, deterministic fragility function illustrated in Figure 3(a). With the values $\left(y_{1, \min }, y_{2, \min }\right)$, the deterministic fragility function is expressed as:

$$
P\left(\mathcal{D}_{T} \mid y_{1}, y_{2}\right)= \begin{cases}1 & \text { if } y_{1} \geq y_{1, \min } \text { and } y_{2} \geq y_{2, \min } \\ 0 & \text { otherwise }\end{cases}
$$

In a general way, the fragility function $P\left(\mathcal{D}_{T} \mid y_{1}, y_{2}\right)$ should be expressed by a bivariate distribution function $F\left(y_{1}, y_{2}\right)$ illustrated by a graph of a univariate function in Figure 3(b). A specification of $F\left(y_{1}, y_{2}\right)$ will face at least two problems:

1. The thermal radiation expressed by the demand variable $y_{1}$ of $P\left(\mathcal{D}_{T} \mid y_{1}, y_{2}\right)$ is generally not constant over the time interval $\left(0, y_{2}\right)$;

2. The probabilities $P\left(\mathcal{D}_{T} \mid y_{1}, y_{2}\right)$ can be uncertain for given pairs $\left(y_{1}, y_{2}\right)$. In terms of PRA, uncertainty of this type is called the epistemic uncertainty (e.g. Sankararaman, Mahadevan 2013). The presence of epistemic uncertainty in values of the fragility function will add complexity to the estimation of the damage probability $P\left(\mathcal{D}_{T} \mid \mathcal{B}\right)$.

The first problem is usually sidestepped by stating that the thermal radiation from a BLEVE fireball is maximal and constant over the last two thirds of fireball duration (e.g. Casal 2008; Dhurandher et al. 2015). In the first third, the radiation is not constant and increases from zero to a maximum value. A simple assumption that the maximum radiation will be emitted over the entire time of fireball life will yield a conservatively large estimate of the damage probability $P\left(\mathcal{D}_{T} \mid \mathcal{B}\right)$.

The presence of the second problem will complicate the estimation of $P\left(\mathcal{D}_{T} \mid \mathcal{B}\right)$. In principle, the epistemic uncertainty in the fragility function $P\left(\mathcal{D}_{T} \mid y_{1}, y_{2}\right)$ should be transformed into one related to the damage probability $P\left(\mathcal{D}_{T} \mid \mathcal{B}\right)$. This transformation is usually done by a Monte Carlo simulation and it yields a random damage probability, say $\widetilde{P}\left(\mathcal{D}_{T} \mid \mathcal{B}\right)$. Then the final result of an estimation of $P\left(\mathcal{D}_{T} \mid \mathcal{B}\right)$ can be a conservative percentile of $\widetilde{P}\left(\mathcal{D}_{T} \mid \mathcal{B}\right)$ (Vaidogas, Juocevičius 2007, 2009; 
(a)

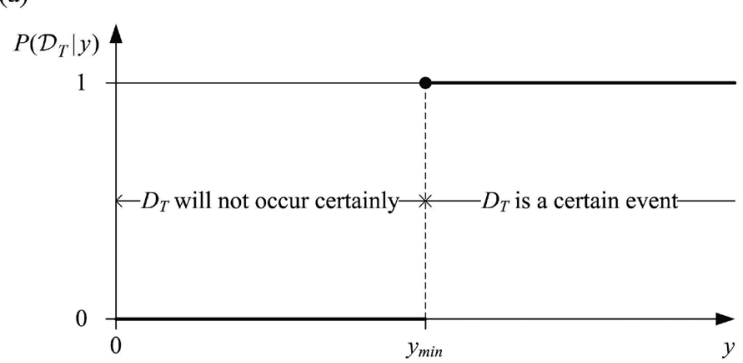

(b)

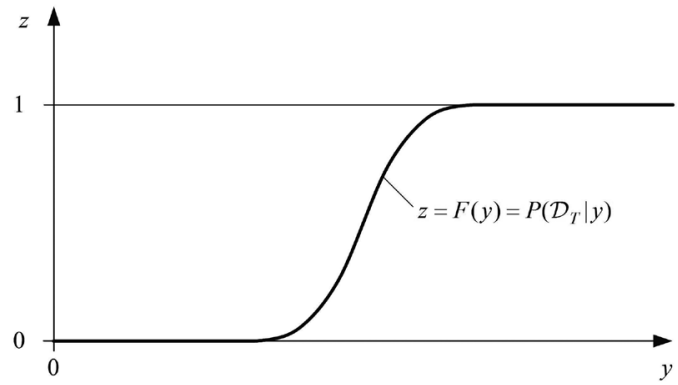

Fig. 3. A schematic, two-dimensional illustration of the fragility function $P\left(\mathcal{D}_{T} \mid \boldsymbol{y}\right)$ : (a) deterministic representation expressed by a single threshold value $y_{\min }$; (b) probabilistic representation by a cumulative distribution function $F(y)$

Vaidogas 2009; Linkutè et al. 2013). Such an estimation results in one single and conservative value of the damage probability $P\left(\mathcal{D}_{T} \mid \mathcal{B}\right)$. A single value is convenient for decision-making and preferable to an interval or information expressed by a density function. Further recipes for dealing with epistemic uncertainties related to fragility functions were proposed by other authors (Celik, Ellingwood 2010; Mandal et al. 2015). However, a unified and commonly recognised approach to handling epistemic uncertainties in structural fragilities has not been developed to date.

Fitting a well-known bivariate density $f(\boldsymbol{y})$ to the direct data on BLEVE effects can be problematic. BLEVE accidents on road are unique, short-lasting and unexpected events. The post mortem data on them is too sparse for fitting $f(\boldsymbol{y})$. However, the density $f(\boldsymbol{y})$ and so the probability $P\left(\mathcal{D}_{T} \mid \mathcal{B}\right)$ can be estimated by propagating uncertainties expressed by the lower-level density $f(\boldsymbol{x})$ through the model $\boldsymbol{\psi}(\boldsymbol{x})$ (e.g. Vaidogas 2007a, 2007b). The function $\psi(x)$ can be composed of a relatively large number of models available currently for the prediction of individual effects of BLEVE. These models are strictly deterministic, some are in competition for modelling individual characteristics of BLEVE fireballs (Abbassi, T., Abbassi, S. A. 2007; Eckhoff 2014). Table 2 contains an example of $\boldsymbol{\psi}(\boldsymbol{x})$ composed of two sub-models $\psi_{1}(\boldsymbol{x})$ and $\psi_{2}(\boldsymbol{x})$ developed for a prediction of fireball radiation $y_{1}$ and duration $y_{2}$, respectively.

The uncertainties related to components of the input vector $\boldsymbol{x}$ call for an introduction of a random vector $\boldsymbol{X}$ described by the p.d.f. $f(\boldsymbol{x})$. With the random input vector
$\boldsymbol{X}$, the output of the model $\psi(\boldsymbol{X})=\left(\psi_{1}(\boldsymbol{X}), \psi_{2}(\boldsymbol{X})\right)$ will be random and can be modelled by two random variables: random thermal radiation $Y_{1}=\psi_{1}(\boldsymbol{X})$ and random fireball duration $Y_{2}=\psi_{2}(\boldsymbol{X})$. The probability distributions of $Y_{1}$ and $Y_{2}$ can be estim ated by applying a simulation-based propagation of uncertainties through the model $\psi(\cdot)$. Values of the random input vector, $\boldsymbol{x}_{j}$, can be sampled from probability distributions of the random components of $\boldsymbol{X}$ and the corresponding output values $y_{1 j}=\psi_{1}\left(\boldsymbol{x}_{j}\right)$ and $y_{2 j}=\psi_{2}\left(\boldsymbol{x}_{j}\right)$ calculated by means of $\boldsymbol{\psi}(\cdot)$. A repetition of this process a large number of times, say, $N$ will yield a Monte Carlo estimate of the damage probability $P\left(\mathcal{D}_{T} \mid \mathcal{B}\right)$, namely:

$$
\hat{P}\left(\mathcal{D}_{T} \mid \mathcal{B}\right)=N^{-1} \sum_{j=1}^{N} \hat{P}\left(\mathcal{D}_{T} \mid y_{1 j}, y_{2 j}\right),
$$

where $\hat{P}\left(\mathcal{D}_{T} \mid \mathcal{B}\right)$ is the estimate of $P\left(\mathcal{D}_{T} \mid \mathcal{B}\right)$ and $\hat{P}\left(\mathcal{D}_{T} \mid y_{1 j}, y_{2 j}\right)$ is an estimate of the fragility function value $P\left(\mathcal{D}_{T} \mid y_{1 j}, y_{2 j}\right)$. The value $\hat{P}\left(\mathcal{D}_{T} \mid \mathcal{B}\right)$ is an estimate of a mean of the fragility function with random arguments, namely, $P\left(\mathcal{D}_{T} \mid Y_{1}, Y_{2}\right)=P\left(\mathcal{D}_{T} \mid \psi_{1}(\boldsymbol{X}), \psi_{2}(\boldsymbol{X})\right)$ (e.g. Vaidogas 2007a, 2007b). The probabilities $P\left(\mathcal{D}_{T} \mid y_{1 j}, y_{2 j}\right)$ can be estimated in the similar manner, namely, by computing the average:

$$
\hat{P}\left(\mathcal{D}_{T} \mid y_{1 j}, y_{2 j}\right)=M^{-1} \sum_{l=1}^{M} 1\left(y_{1 j}, y_{2 j}, z_{l}\right),
$$

where $M$ is the number of Monte Carlo simulations; $\mathbf{1}(\cdot)$ is an indicator function and $\boldsymbol{z}_{l}$ is the vector of random characteristics of exposed roadside object sampled in the simulation step $l$. The function $\mathbf{1}(\cdot)$ must

Table 2. Components (sub-models) of the model $\boldsymbol{\psi}(\boldsymbol{x})=\left(\psi_{1}(\boldsymbol{x}) \psi_{2}(\boldsymbol{x})\right.$ developed in by the Dutch organisation TNO (CPD 2005) (components of the input vector $\boldsymbol{x}$ are explained in Table 3)

\begin{tabular}{llc}
\hline \multicolumn{1}{c}{ Component of $\psi(\boldsymbol{x})$} & Description & Expression of the sub-model \\
\hline$\psi_{1}(\boldsymbol{x})$ & Intensity of thermal radiation & $\psi_{1}(\boldsymbol{x})=E(\boldsymbol{x}) F_{\text {view }}(\boldsymbol{x}) \tau_{\mathrm{a}}(\boldsymbol{x}) *$ \\
\hline$\psi_{2}(\boldsymbol{x})$ & Fireball duration & $\psi_{2}(\boldsymbol{x})=0.852\left(x_{4} x_{5} x_{6}\right)^{0.8}$ \\
\hline$* E(\boldsymbol{x})=E\left(x_{1}, x_{2}, \ldots, x_{12}\right)$ & is the emissive power of the fireball surface; $F_{\text {view }}(\boldsymbol{x})=F_{\text {view }}\left(x_{1}, x_{2}, \ldots, x_{6}\right)$ is the view factor; \\
$\tau_{\mathrm{a}}(\boldsymbol{x})=\left(x_{1}, x_{2}, \ldots, x_{6}, x_{13}, x_{14}\right)$ & is the atmospheric transitivity; see CPD $(2005)$ for a detailed description of the sub-models $E(\cdot)$, \\
$F_{\text {view }}(\cdot)$ and $\tau_{\mathrm{a}}(\cdot)$ &
\end{tabular}


Table 3. Input vector $\boldsymbol{x}$ of the model $\boldsymbol{\psi}(\boldsymbol{x})$

\begin{tabular}{clcc}
\hline Component of $\boldsymbol{x}$ & \multicolumn{1}{c}{ Description } & Units & Value** \\
\hline$x_{1}$ & Position of the BLEVE centre along the axis $\left\{0 ; x_{1}\right\}$ (Fig. 4) & $\mathrm{m}$ & Random, see Table 5 \\
\hline$x_{2}$ & Position of the BLEVE centre along the axis $\left\{0 ; x_{2}\right\}$ (Fig. 4) & $\mathrm{m}$ & Random, see Table 5 \\
\hline$x_{3}$ & Position of the BLEVE centre along the axis $\left\{0 ; x_{3}\right\}$ (Fig. 5) & $\mathrm{m}$ & 0.0 \\
\hline$x_{4}$ & Capacity of the tank & $\mathrm{m}^{3}$ & 56.14 \\
\hline$x_{5}$ & Pressure in the vessel just before the explosion* & $\mathrm{N} / \mathrm{m}^{2}$ & $20 \times 10^{5}$ \\
\hline$x_{6}$ & Degree of tank filling & $\%$ & Random, see Table 5 \\
\hline$x_{7}$ & Density of LPG (propane) & $\mathrm{kg} / \mathrm{m}^{3}$ & 585 \\
\hline$x_{8}$ & Combustion heat of LPG at its boiling point & $\mathrm{J} / \mathrm{kg}$ & $46.0 \times 10^{6}$ \\
\hline$x_{9}$ & Vaporisation heat of LPG at its boiling point & $\mathrm{J} / \mathrm{kg}$ & $0.426 \times 10^{6}$ \\
\hline$x_{10}$ & Specific heat capacity at constant pressure & $\mathrm{J} /\left(\mathrm{kg}{ }^{\circ} \mathrm{K}\right.$ ) & 0.002582 \\
\hline$x_{11}$ & Temperature of the fireball flame & ${ }^{\circ} \mathrm{K}$ & Random, see Table 5 \\
\hline$x_{12}$ & Partial vapour pressure of carbon dioxide in the atmosphere & $\mathrm{N} / \mathrm{m}^{2}$ & 30.39 \\
\hline$x_{13}$ & Ambient temperature & ${ }^{\circ} \mathrm{C}$ & Random, see Table 5 \\
\hline$x_{14}$ & Relative humidity & $\%$ & Random, see Table 5 \\
\hline
\end{tabular}

* Relief pressure of the safety valve can be assumed as the pressure at the instant of explosion (Casal 2008).

** The values presented in this column will be used in the example case study described in Section 3.

be defined so that for a given triplet $\left(y_{1 j}, y_{2 j}, z_{l}\right)$ the values $\mathbf{1}\left(y_{1 j}, y_{2 j}, \boldsymbol{z}_{l}\right)=1$ and $\mathbf{1}\left(y_{1 j}, y_{2 j}, \boldsymbol{z}_{l}\right)=0$ indicate an occurrence and non-occurrence of $\mathcal{D}_{T}$, respectively. Eqns (7) realise a nested loop simulation procedure. The accuracy of the estimate $\hat{P}\left(\mathcal{D}_{T} \mid \mathcal{B}\right)$ will increase with increasing numbers of simulations, $M$ and $N$. Eqns (7) are widely used in the field of structural reliability.

\section{Example case study}

The potential thermal damage from a road tanker BLEVE fireball to the $1^{\text {st }}$ of the four reservoirs shown in Figure 4 will be analysed. The reservoirs are located in the Lithuanian capitol Vilnius in the vicinity of the A1 highway (Fig. 4(a)).

The thermal radiation will be estimated at the centre of reservoir roof, where system components sensitive to thermal radiation are installed (point " $\Pi_{1}$ "), and at the bottom of the diked area around the reservoirs, were piping and other system components are attached to the reservoir (point " $\Pi_{2}$ ") (Fig. 5). Characteristics of the points " $\Pi_{1}$ " and " $\Pi_{2}$ " are given in Table 4. A BLEVE of a typical road tanker semi-truck carrying 24.7 tons of propane will be considered.
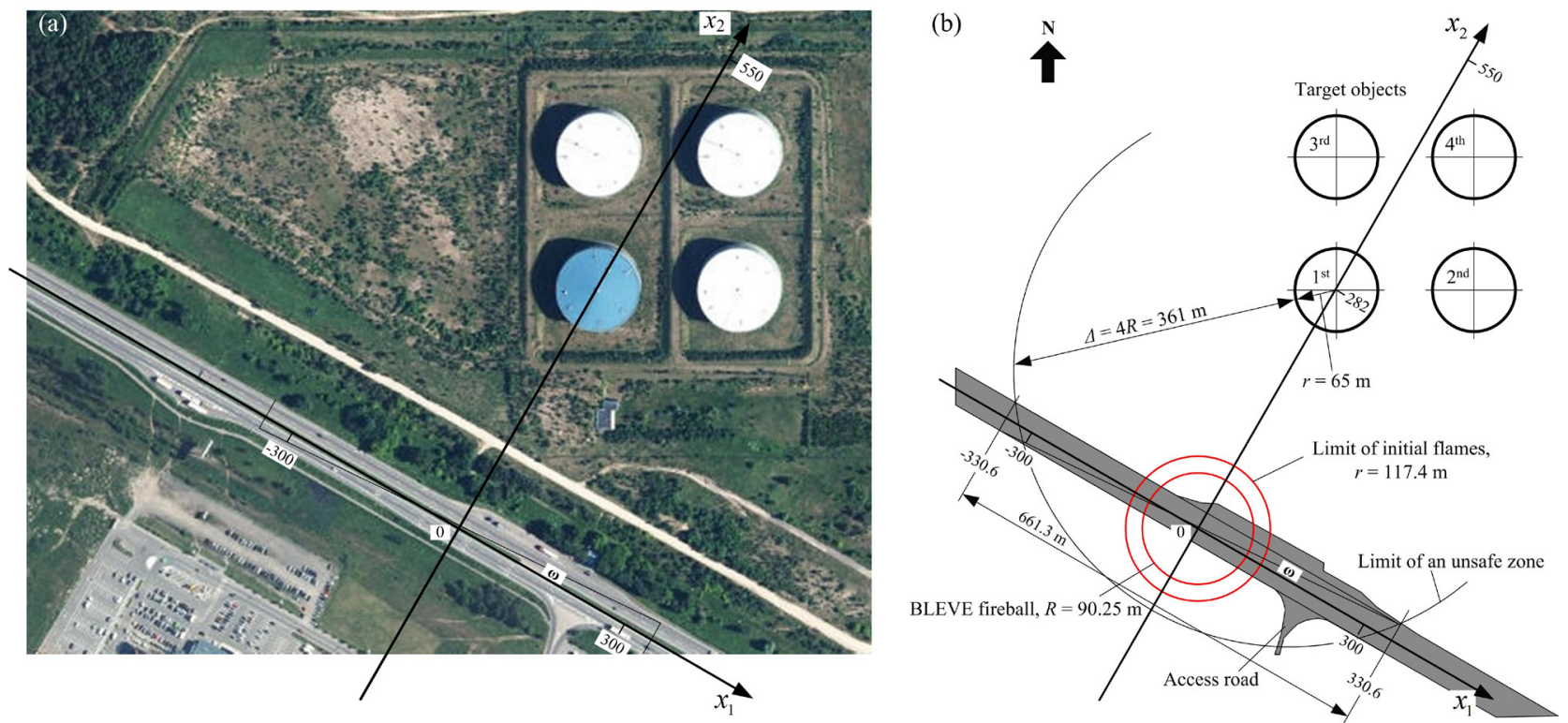

Fig. 4. An example of external exposure of a potential target to a BLEVE on road: (a) an aerial view of four reservoirs with flammable materials located in the vicinity of a road with a frequent transportation of liquefied gases; (b) schematic view with a coordinate system $\left\{0 ; x_{1}, x_{2}\right\}$ based on road centreline and cylinder axis of one of the reservoirs 


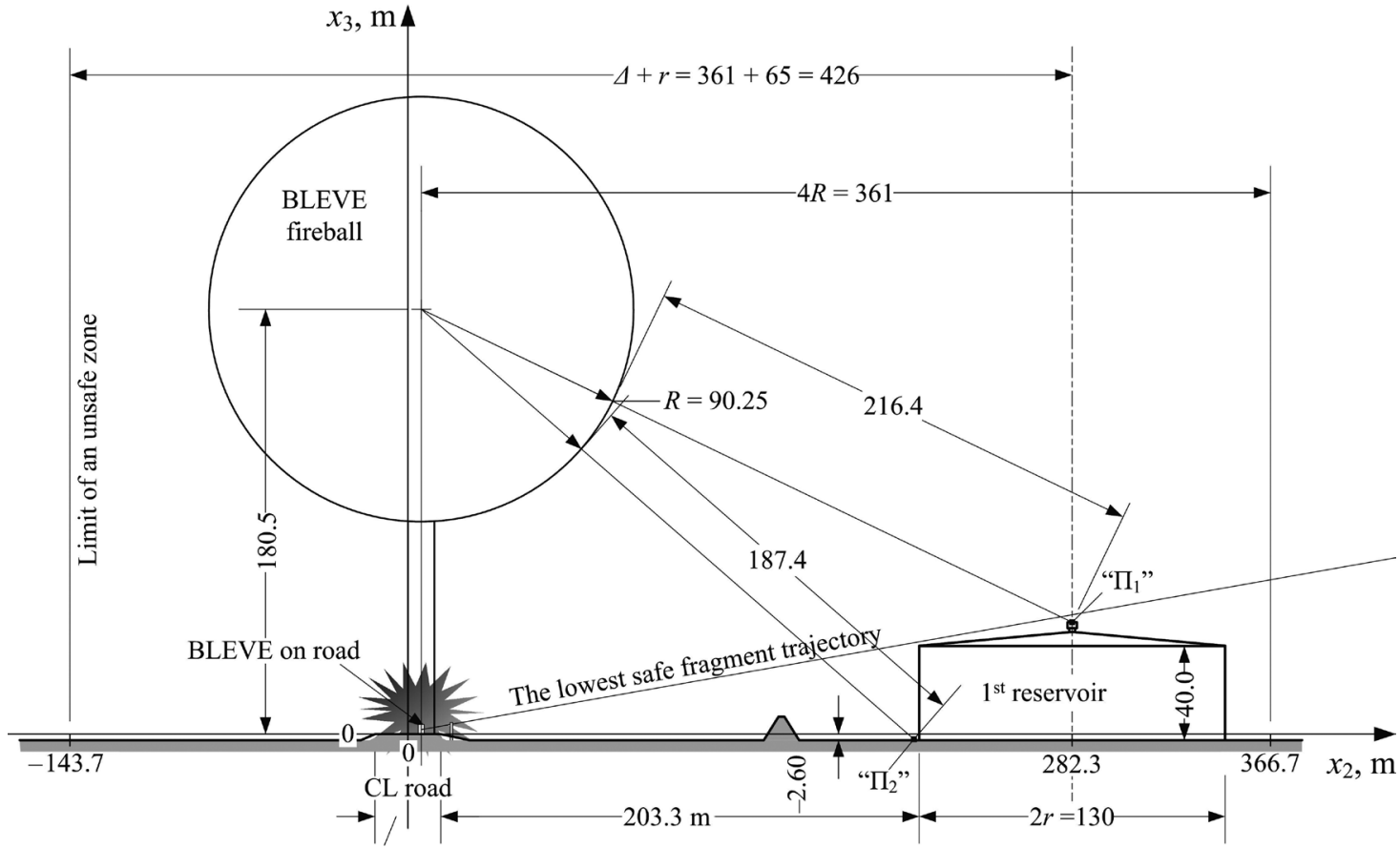

Four-lane road with $3.75 \mathrm{~m}$ lanes; width of all road elements is $28.0 \mathrm{~m}$

Fig. 5. Exposure of a roadside object (target) to the fireball generated by a BLEVE of a road tanker carrying 24.7 tons of propane (the dimensions of the fireball were estimated by means of the TNO model given in CPD (2005))

The BLEVE can occur on an unsafe road segment $\omega$ with the length of $661.3 \mathrm{~m}$ (Fig. 2(b)). The area between the road and the reservoirs is flat; the road segment $\omega$ has a negligible gradient. The road has four lanes, each $3.75 \mathrm{~m}$ wide and a $5,5 \mathrm{~m}$ wide median which separates opposing lanes of traffic (Fig. 6(b)). The LPG is transported along the road segment $\omega$ with relative frequencies $\pi_{1}=0.35, \pi_{2}=0.04, \pi_{3}=0.07$ and $\pi_{4}=0.54$ shown in Figure 6(a). These frequencies were obtained from an observation of traffic in the road segment $\boldsymbol{\omega}$.
The BLEVE accident is described by the vector $\boldsymbol{X}$ defined by the equation:

$$
\begin{gathered}
\boldsymbol{X}=\left(X_{1}, X_{2}, X_{3}, x_{4}, x_{5}, X_{6}, x_{7}, x_{8}, x_{9}, x_{10},\right. \\
\left.X_{11}, x_{12}, X_{13}, X_{14}\right) .
\end{gathered}
$$

Components of $\boldsymbol{X}$ are explained in Table 3. This table gives values of the deterministic components of this vector, $x_{4}, x_{5}, x_{7}, x_{8}, x_{9}, x_{10}$ and $x_{12}$. The probability distribution of the longitudinal rest position of the road tanker and so the position of a potential BLEVE centre, $X_{1}$, was

(a)

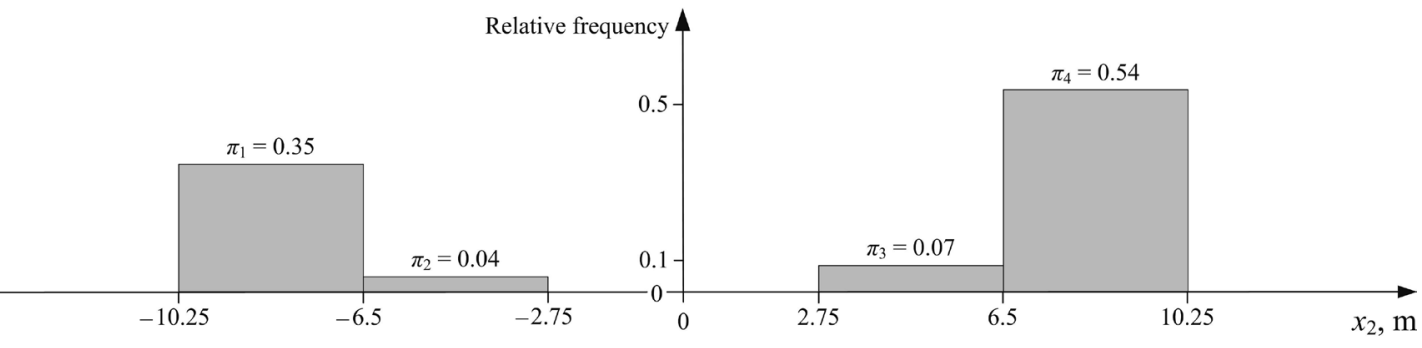

(b)

$$
\text { Lane } 1 \quad \text { Lane } 2 \quad \text { CL road }
$$

Lane 3

Lane 4

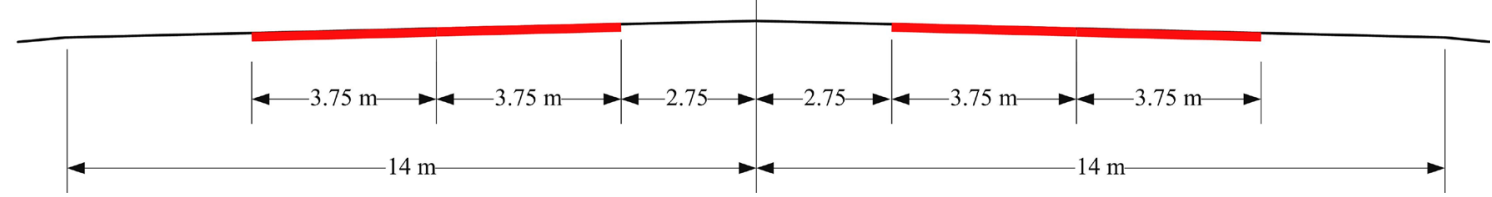

Fig. 6. Simulation of the transverse rest position of road tanker which can sustain a BLEVE: (a) relative frequencies of transporting liquefied gases through individual lanes; (b) transverse profile of the road (the symbol CL denotes the road centreline) 
Table 4. Characteristics of two vulnerable points in the reservoir system that can be ignited by a BLEVE fireball

\begin{tabular}{|c|c|c|c|c|}
\hline \multirow{2}{*}{ Point } & \multirow{2}{*}{$\begin{array}{l}\text { Position in the coordinate system } \\
\qquad\left\{0 ; x_{1}, x_{2}, x_{3}\right\}\end{array}$} & \multicolumn{2}{|c|}{ Criterion of thermal damage } & \multirow{2}{*}{$\begin{array}{l}\text { Estimate of damage probability, } \\
\left.\hat{P}_{k}\left(\mathcal{D}_{T} \mid \mathcal{B}\right)^{*} \text { (see Eqns }(7)\right)\end{array}$} \\
\hline & & $y_{1, \min }\left(\mathrm{kW} / \mathrm{m}^{2}\right)$ & $y_{2, \min }(\mathrm{s})$ & \\
\hline$\Pi_{1}$ & $(0 \mathrm{~m}, 282.3 \mathrm{~m}, 47.5 \mathrm{~m})$, Fig. 5 & 25 & 10 & $\hat{P}_{1}\left(\mathcal{D}_{T} \mid \mathcal{B}\right)=1.021 \times 10^{-3}$ \\
\hline$\Pi_{2}$ & $(0 \mathrm{~m}, 215 \mathrm{~m},-2.17 \mathrm{~m})$, Fig. 5 & 30 & 10 & $\hat{P}_{2}\left(\mathcal{D}_{T} \mid \mathcal{B}\right)=0.1814$ \\
\hline
\end{tabular}

* Computed with $N=1 \times 10^{5}$ with $k=1$ and $k=2$ standing for the points $\Pi_{1}$ and $\Pi_{2}$, respectively.

Table 5. Probability distributions of the random components of the vector $\boldsymbol{X}$ used to describe a road tanker BLEVE accident

\begin{tabular}{cccl}
\hline Random variable & Mean & $\begin{array}{c}\text { Coefficient of variation } \\
\text { (standard deviation) }\end{array}$ & \multicolumn{1}{c}{ Probability distribution } \\
\hline$X_{1}$ & $335.1^{*} \mathrm{~m}$ & $0.577(193.4 \mathrm{~m})$ & Uniform over the length of $\omega$ \\
\hline$X_{2}$ & $2.174 \mathrm{~m}$ & $5.20(11.31 \mathrm{~m})$ & Mixed distribution with the p.d.f. in Eqn $(9)$ \\
\hline$X_{6}$ & 0.85 & $0.05(0.0425)$ & Normal \\
\hline$X_{11}$ & $2000^{\circ} \mathrm{K}$ & $0.11\left(220^{\circ} \mathrm{K}\right)$ & Lognormal \\
\hline$X_{13}$ & $15^{\circ} \mathrm{C}$ & $0.20\left(3{ }^{\circ} \mathrm{C}\right)$ & Normal \\
\hline$X_{14}$ & $70^{\circ}$ & $0.1(7 \%)$ & Normal \\
\hline
\end{tabular}

*In the accident simulation the mean value of $X_{1}$ was shifted to the zero value of the axis $\left\{0 ; x_{1}\right\}$.

assumed to be uniformly distributed over the length of $\omega$ (Fig. 4(b), Table 5). This distribution expresses maximum uncertainty related to a potential BLEVE centre along the axis $\left\{0 ; x_{1}\right\}$. The road segment did not experience tanker truck accidents in previous years.

The probability distribution of the transverse tank position after it comes to a complete stop and can explode, $X_{2}$, depends on the lane of intended travel. Our previous analysis of tank car accident data led to the result that the transverse rest position of the tank centre with respect to the centreline of intended travel lane can be modelled by a logistic distribution Logistic (2.02 m, $3.10 \mathrm{~m})$ (Vaidogas et al. 2012a, 2012b). The positive location parameter of this distribution, $2.02 \mathrm{~m}$, means that the transverse rest position lays in average $2.02 \mathrm{~m}$ outwards the travel lane centreline. The distribution Logistic $(2.02 \mathrm{~m}, 3.10 \mathrm{~m})$ can be associated with each of the four lanes of the road under consideration by adding (subtracting) its location parameter to (from) the coordinate of the lane centreline along the axis $\left\{0 ; x_{2}\right\}$ (Fig. 7(a)). This will allow constructing a mixed p.d.f. of $X_{2}$, in which the frequencies $\pi_{1}$ to $\pi_{4}$ will play the role of probabilistic weights:

$$
\begin{gathered}
\varphi\left(x_{2}\right)=\pi_{1} f_{1}\left(x_{2} \mid-10.4,3.10\right)+\pi_{2} f_{2}\left(x_{2} \mid-6.65,3.10\right)+ \\
\pi_{3} f_{3}\left(x_{2} \mid 6.65,3.10\right)+\pi_{4} f_{4}\left(x_{2} \mid 10.4,3.10\right)
\end{gathered}
$$

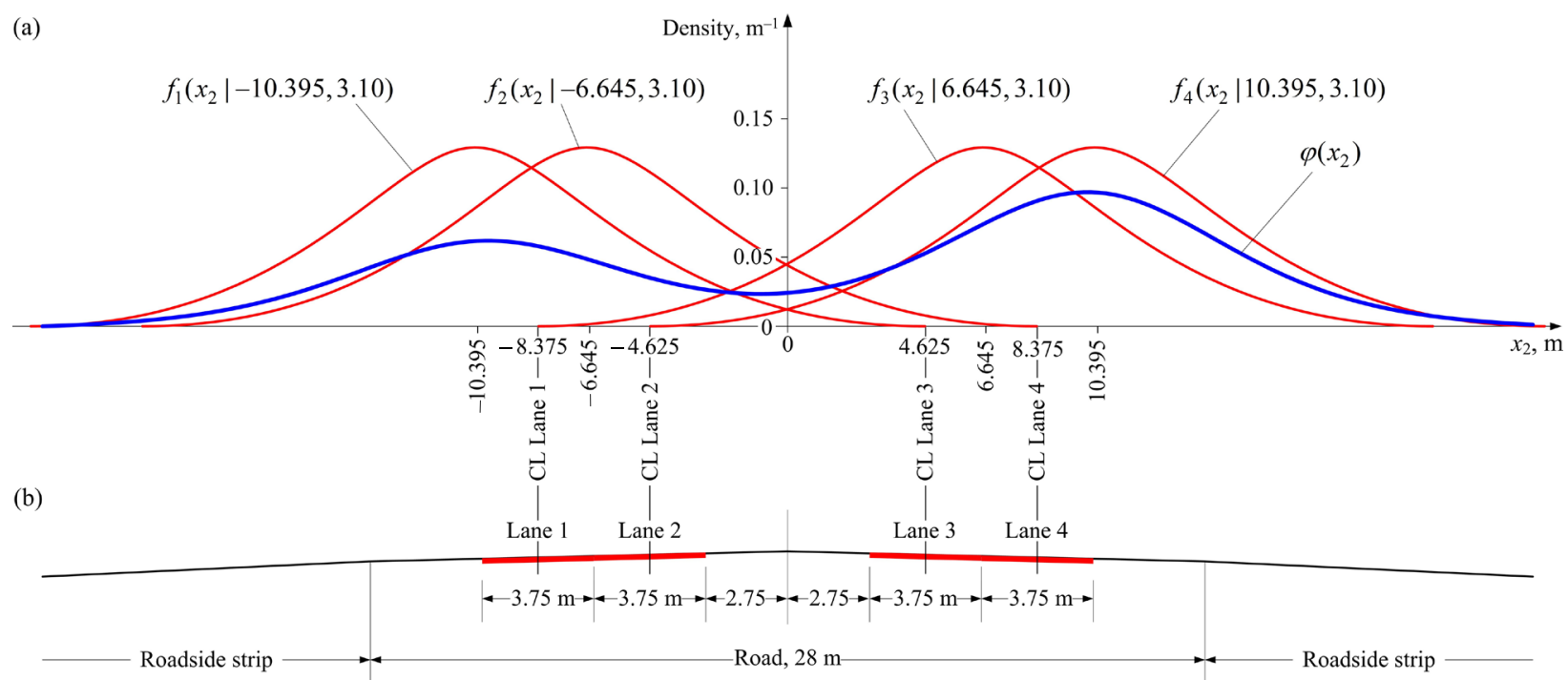

Fig. 7. Probabilistic model of the transverse rest position of the tank: (a) densities of the transverse departure from the centrelines (CLs) of individual lanes and a mixture of these densities, $\varphi\left(x_{2}\right)$; (b) road profile and adjacent roadside territory 
where $\varphi\left(x_{2}\right)$ denotes the mixed p.d.f. of $X_{2}$ and $f_{l}\left(x_{2} \mid \cdot, \cdot\right)$ $(l=1,2,3,4)$ are the logistic p.d.f.s related to the respective travel lanes. Parameters of the densities $f_{l}\left(x_{2} \mid \cdot, \cdot\right)$ in Eqn (9) are in meters. The graph of the bimodal density $\varphi\left(x_{2}\right)$ is shown in Figure 7(a). The probability distributions of the remaining random variables considered in the present example, $X_{6}, X_{11}, X_{13}$ and $X_{14}$, were assumed by following the recommendations given by Papazoglou and Aneziris (1999) who considered the quantification of uncertainties related to the BLEVE thermal radiation.

The values $\boldsymbol{x}_{j}=\left(x_{1 j}, x_{2 j}\right)$ of the random input vector $\boldsymbol{X}$ were sampled by means of a stochastic simulation from the probability distributions listed in Table 5. Then the simulated values $\boldsymbol{x}_{j}$ and the model $\boldsymbol{\psi}(\cdot)$ described in Table 2 were used to compute values of the thermal radiation and fireball duration, $y_{1 j}$ and $y_{2 j}$. The simulation was repeated $1 \times 10^{5}$ times $(N=100000)$. The simulated values of the thermal radiation, $y_{1 j}=\psi_{1}\left(\boldsymbol{x}_{j}\right)$, were different in the points " $\Pi_{1}$ " and " $\Pi_{2}$ ", because the simulated input vectors $\boldsymbol{x}_{j}$ involved different positions of " $\Pi_{1}$ " and " $\Pi_{2}$ ".
The symbol $y_{1 j k}(k=1,2)$ will be used to signify this difference, where the values $k=1$ and $k=2$ stand for the points " $\Pi_{1}$ " and " $\Pi_{2}$ ", respectively. The simulated values $y_{1 j k}$ were used for composing two samples:

$$
\hat{\boldsymbol{y}}_{1 k}=\left\{y_{1 j k}, j=1,2, \ldots, N\right\}(k=1,2) .
$$

The simulated values of the fireball duration, $y_{2 j}=\psi_{2}\left(\boldsymbol{x}_{j}\right)$, did not depend on the position of exposed roadside object (location of the points " $\Pi_{1}$ " and " $\Pi_{2}$ "). These values were used to compose the sample:

$$
\hat{\boldsymbol{y}}_{2}=\left\{y_{2 j}, j=1,2, \ldots, N\right\} .
$$

Descriptive measures of the samples $\hat{\boldsymbol{y}}_{1 k}$ and $\hat{\boldsymbol{y}}_{2}$ are given in Table 6. Figure 8 shows scatter diagrams of the pairs $\left(x_{1 j}, x_{2 j}\right)$ and $\left(y_{1 j 2}, y_{2 j}\right)(j=1,2, \ldots, 10000)$.

With the pairs $\left(y_{1 j k}, y_{2 j}\right)$, estimates of the probability of thermal damage, $\hat{P}_{k}\left(\mathcal{D}_{T} \mid \mathcal{B}\right)$, were computed for points " $\Pi_{k} "(k=1,2)$ (see Table 4). Descriptive measures given

Table 6. Descriptive measures of the samples $\hat{\boldsymbol{y}}_{1 k}$ and $\hat{\boldsymbol{y}}_{2}$ composed of 100000 simulated values of thermal radiation and fireball duration and estimated in the points " $\Pi_{k}$ " $(k=1,2)$

\begin{tabular}{cccccc}
\hline Point(s)* & Sample** & Mean & Coeff. of variation & $($ min, max $)$ & $95^{\text {th }}$ percentile \\
\hline " $\Pi_{1} "$ & $\hat{\boldsymbol{y}}_{11}$ & $16.61 \mathrm{~kW} / \mathrm{m}^{2}$ & $23.4 \%$ & $\left(9.09 \mathrm{~kW} / \mathrm{m}^{2}, 27.58 \mathrm{~kW} / \mathrm{m}^{2}\right)$ & $22.58 \mathrm{~kW} / \mathrm{m}^{2}$ \\
\hline " $\Pi_{2} "$ & $\hat{\boldsymbol{y}}_{12}$ & $19.51 \mathrm{~kW} / \mathrm{m}^{2}$ & $26.4 \%$ & $\left(9.57 \mathrm{~kW} / \mathrm{m}^{2}, 32.72 \mathrm{~kW} / \mathrm{m}^{2}\right)$ & $27.44 \mathrm{~kW} / \mathrm{m}^{2}$ \\
\hline " $\Pi_{1}$ " and " $\Pi_{2} "$ & $\hat{\boldsymbol{y}}_{2}$ & $12.20 \mathrm{~s}$ & $1.301 \%$ & $(11.47 \mathrm{~s}, 12.78 \mathrm{~s})$ & $12.45 \mathrm{~s}$ \\
\hline
\end{tabular}

* See Figure 5 .

**The samples are defined by Eqns (10), $N=100000$.

(a)

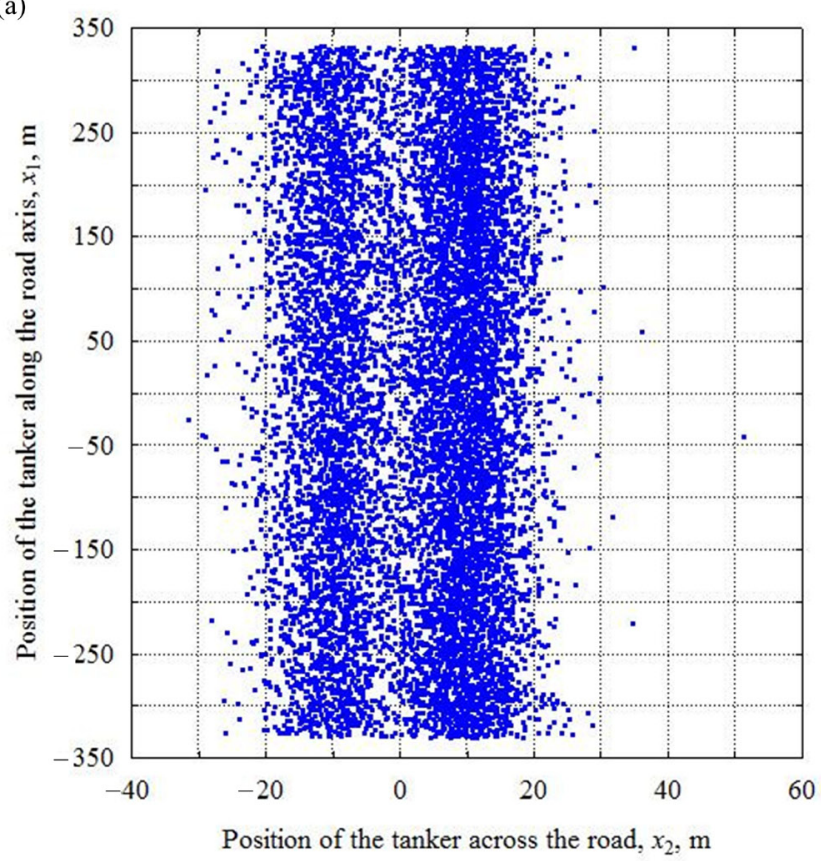

(b)

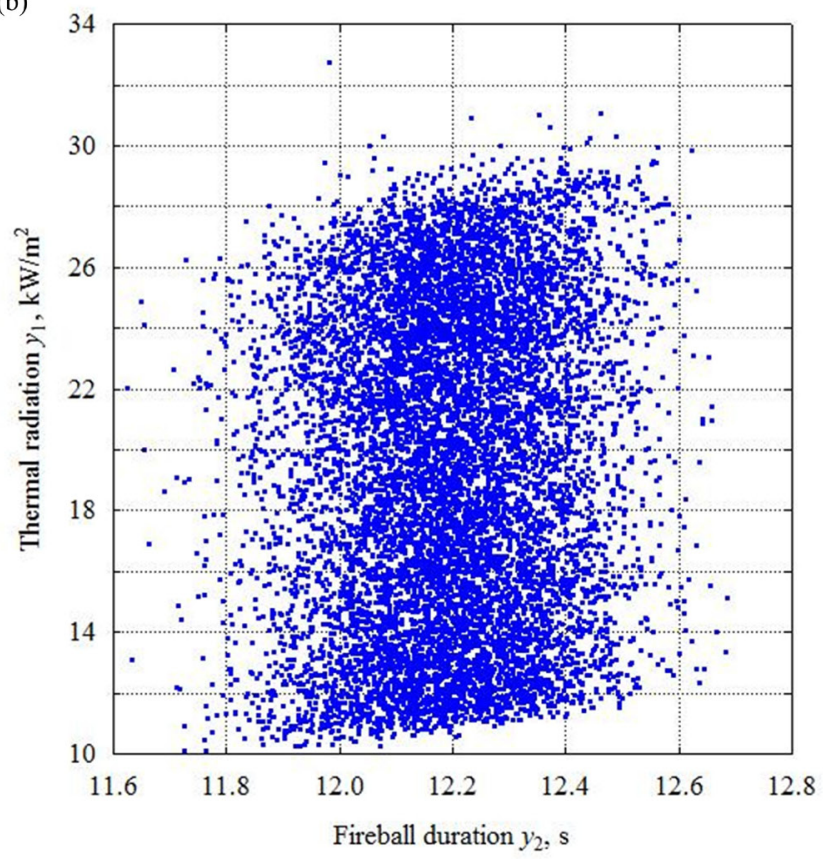

Fig. 8. Results of the simulation of a BLEVE thermal radiation at point " $\Pi_{2}$ " shown in Figure 5: (a) simulated positions of the road tank, $\left(x_{1 j}, x_{2 j}\right)$; (b) simulated pairs of the thermal radiation and fireball duration, $\left(y_{1 j}, y_{2 j}\right)(j=1,2, \ldots, 10000)$ 
in Table 6 and values of the estimates $\hat{P}_{k}\left(\mathcal{D}_{T} \mid \mathcal{B}\right)$ make it clear that the point " $\Pi_{2}$ " is much more vulnerable to thermal radiation than " $\Pi_{1}$ ". Consequently, a thermal insulation (shielding) should be provided in order to protect this part of the reservoir system against BLEVE.

\section{Conclusions}

An assessment of transportation infrastructure in terms of potential risks has been considered. The attention was focused on roads and railways used for transportation of hazardous materials. The prime objective of this study was to explore the possibility of assessing individual road and railway segments which can pose risk to roadside objects in terms of mechanical and thermal damage. Results of the study led to the following conclusions:

1. The existing configuration of land transport network is such that objects built in the vicinity of many road and railway segments can be damaged during accidents occurring occasionally on road and rail. Such accidents manifest themselves as fires and explosions of vehicles carrying hazardous materials. They induce thermal and mechanical effects capable to cause damage in the roadside territory. Materials most often involved in transportation accidents and so in fires and explosions are commercial energetic hydrocarbons.

2. Statistical data on hazardous materials transportation accidents collected in the previous decade indicates that fires on road and rail are somewhat more often than explosions. However, the latter have higher damaging potential than the former. The main two types of explosions of hydrocarbon cargos are BLEVE and VCE. BLEVEs of road and railway tankers are more likely than VCEs. The damaging potential of BLEVE is larger than the one of VCE, because BLEVE can induce both thermal and mechanical effects on roadside territory, whereas VCE poses mainly mechanical effect which in most cases will be relatively weak. In transportation, BLEVEs occur as catastrophic failures of vessels of tanker trucks and tank cars. They are usually preceded by traffic accidents of trucks and trains.

3. Probabilistic risk analysis is a natural platform suitable for assessing an individual road or railway segment in terms of risk posed by a potential BLEVE on road or rail to roadside territory. In line with this analysis, such a risk can be expressed as a frequency of a specific thermal and/or mechanical damage to a vulnerable roadside object. Typically this frequency is an annual one. The damage frequency can serve as a measure of criticality of a road or railway segment with the potentiality of a BLEVE accident. The higher it is the more critical is the segment.

4. An estimation of damage frequency will require assessing the entire configuration of road or railway segment under analysis and adjacent roadside territory with vulnerable built objects. In addition, fra- gility functions will have to be developed for the objects of interest. The demand variables of these functions will be effects of BLEVE: thermal radiation, characteristics of fragment impact, overpressure and incidence angle of a blast wave. The frequency estimation will also require predicting these effects by means of mathematical modelling.

5. Uncertainties related to a BLEVE of a road tanker should be modelled by means probability distributions and can be propagated by applying a stochastic simulation (Monte Carlo method). The basis for such simulation is deterministic models of BLEVE effects developed among others by the Dutch organisation TNO. The lowest level uncertainties will be related to input of these models. Part of the input are variables specifying the position of explosion centre with respect to a potential roadside target. This position will be determined by the geometrical configuration of the road segment or railway under analysis. The spread of BLEVE effects may be influenced by the character of roadside territory and position of potential target in this territory. These two points relate analysis of road infrastructure to an assessment of risk induced by fire and explosion accidents on road.

The assessment of road segments through estimating risk posed to roadside territory was illustrated by an example case study. A possible effect of thermal radiation induced by a BLEVE of a propane tanker truck was considered. The vulnerable roadside object under analysis was a reservoir built in the vicinity of a road used for an intense transportation of hazardous materials. The risk was assessed by estimating the probabilities of thermal damage to two vulnerable points of the reservoir.

\section{References}

Abbasi, T.; Abbasi, S. A. 2007. The boiling liquid expanding vapour explosion (BLEVE): mechanism, consequence assessment, management, Journal of Hazardous Materials 141(3): 489-519.

http://dx.doi.org/10.1016/j.jhazmat.2006.09.056

Anderson, C. E.; Riegel, J. P. 2015. A penetration model for metallic targets based on experimental data, International Journal of Impact Engineering 80: 24-35. http://dx.doi.org/10.1016/j.ijimpeng.2014.12.009

Babrauskas, V. 2003. Ignition handbook. Issaquah: Fire Science Publishers. $1116 \mathrm{p}$.

Baublys, A. 2003. Direktyvos 94/55/EB dèl valstybiu nariu istatymu, reglamentuojančiu pavojingu kroviniu vežima keliu transportu, suderinimo ir direktyvos 96/49/EB dèl valstybiu nariu istatymu, susijusiu su pavojingu kroviniu vežimu geležinkeliais, suderinimo bei direktyvos 2000/62/Eb papildančios direktyva 96/49/EB igyvendinimo pasekmin tyrimas. Galutinè ataskaita. Europos Komitetas prie Lietuvos Respublikos vyriausybès (in Lithuanian) [online], [cited 10 September 2015]. Available from Internet: https:// www.urm.lt/uploads/default/documents/uzienio_politika/ ES/ES_tyrimai/36_\%20Pavojingi_kroviniai_ataskaita.pdf

Birk, A. M. 1996. Hazards from propane BLEVESs: an update and proposal for emergency responders, Journal of Loss Prevention in the Process Industries 9(2): 173-181. http://dx.doi.org/10.1016/0950-4230(95)00046-1 
Bonilla Martinez, J. M.; Belmonte Perez, J.; Marin Ayala, J. A. 2012. Analysis of the explosion of a liquefied-natural-gas road tanker, Securidad y Medio Ambiente 32: 1-20002E.

Casal, J. 2008. Evaluation of the effects and consequences of major accidents in industrial plants. Amsterdam etc.: Elsevier. 378 p.

CCPS. 1994. Guidelines for evaluating the characteristics of vapor cloud explosions, flash fires, and BLEVEs. New York: Center for Chemical Process Safety of AIChE. 387 p.

Celik, O. C.; Ellingwood, B. R. 2010. Seismic fragilities for non-ductile reinforced concrete frames - role of aleatoric and epistemic uncertainties, Structural Safety 32(1): 1-12. http://dx.doi.org/10.1016/j.strusafe.2009.04.003

Chang, A. S.; Tsai, C. Y. 2015. Difficulty and reasons for sustainable roadway design - the case from Taiwan, Journal of Civil Engineering and Management 21(4): 395-406. http://dx.doi.org/10.3846/13923730.2013.802724

Coffield, A.; Adeli, H. 2014. An investigation of the effectiveness of the framing systems in steel structures subjected to blast loading, Journal of Civil Engineering and Management 20(6): 767-777. http://dx.doi.org/10.3846/13923730.2014.986667

CPD. 2005. Methods for the calculation of physical effects due to releases of hazardous materials (liquids and gases) "Yellow book". Publication Series on Dangerous Substances (PGS2). The Hague: Committee for the Prevention of Disasters. $870 \mathrm{p}$.

Dekker, S. W. A. 2014. The bureaucratization of safety, Safety Science 70: 348-357. http://dx.doi.org/10.1016/j.ssci.2014.07.015

Demir, E.; Huang, Y.; Scholts, S. Van Woensel, T. 2015. A selected review on the negative externalities of the freight transportation: Modeling and pricing, Transportation Research Part E: Logistics and Transportation Review 77: 95-114. http://dx.doi.org/10.1016/j.tre.2015.02.020

Dhurandher, B. K.; Kumar, R.; Dhiman, A. 2015. Impact assessment of thermal radiation hazard from LPG fireball, Procedia Earth and Planetary Science 11: 499-506. http://dx.doi.org/10.1016/j.proeps.2015.06.050

Eckhoff, R. K. 2014. Boiling liquid expanding vapour explosions (BLEVEs): a brief review, Journal of Loss Prevention in the Process Industries 32: 30-43. http://dx.doi.org/10.1016/j.jlp.2014.06.008

Eichler, T. V.; Napadentsky, H. S. 1977. Accidental vapour phase explosions on transportation routes near nuclear power plants. Final Report prepared to US Nuclear Regulatory Commission. NUREG, No NUREG/CR-0075, Washington.

FACTS. 2014. Hazardous materials accidents knowledge base [online], [cited 18 April 2014]. Available from Internet: http://factsonline.nl/browse-chemical-accidents-in-database

Hemmatian, B.; Planas, E.; Casal, J. 2015. Fire as a primary event of accident domino sequences: the case of BLEVE, Reliability Engineering \& System Safety 139: 141-148. http://dx.doi.org/10.1016/j.ress.2015.03.021

Høj, N. P.; Kröger, W. 2002. Risk analysis of transportation on road and railway from a European perspective, Safety Science 40(1-4): 337-357.

http://dx.doi.org/10.1016/S0925-7535(01)00053-4

IAEA. 2003. External events excluding earthquakes in the design of nuclear power plants. Safety Gguide No.NS-G-1.9. International Atomic Energy Agency, Vienna. 105 p.

Kavalov, B.; Petric, H.; Georgakaki, A. 2007. Liquefied natural gas for Europe - some important issues for consideration. JRC Reference Report. European Communities, Luxembourg. $30 \mathrm{p}$.

Kumamoto, H. 2007. Satisfying safety goals by probabilistic risk assessment. London: Springer. 253 p.
Laboureur, D.; Birk, A. M.; Buchlina, J. M.; Rambauda, P.; Aprinc, L.; Heymes, F.; Osmont, A. 2015. A closer look at BLEVE overpressure, Process Safety and Environmental Protection 95(5): 159-171. http://dx.doi.org/10.1016/j.psep.2015.03.004

Landucci, G.; Tugnoli, A.; Busini, V.; Derudi, M.; Rota, R.; Cozzani, V. 2011. The Viareggio LPG accident: Lessons learnt, Journal of Loss Prevention in the Process Industries 24(4): 466-476. http://dx.doi.org/10.1016/j.jlp.2011.04.001

Lenoir, E. M.; Davenport, J. A. 1993. A survey of vapor cloud explosions: second update, Process Safety Progress 12(1): 12-33. http://dx.doi.org/10.1002/prs.680120104

Linkute, L; Juocevičius, V.; Vaidogas, E. R. 2013. A probabilistic design of sacrificial cladding for a blast wall using limited statistical information on blast loading, Mechanika 19(1): 58-66. http://dx.doi.org/10.5755/j01.mech.19.1.3621

Lisi, R.; Consolo, G.; Maschio, G.; Milazzo, M. F. 2015. Estimation of the impact probability in domino effects due to the projection of fragments, Process Safety and Environmental Protection 93: 99-110. http://dx.doi.org/10.1016/j.psep.2014.05.003

Mandal, T. K.; Ghosh, S.; Pujari, N. N. 2015. Seismic fragility analysis of a typical Indian PHWR containment: comparison of fragility models, Structural Safety 58: 11-19. http://dx.doi.org/10.1016/j.strusafe.2015.08.003

Mébarki, A.; Jerez, S.; Matasic, I.; Prodhomme, G.; Reimeringer, M. 2012. Explosions and structural fragments as industrial hazard: domino effect and risks, Procedia Engineering 45: 159-166. http://dx.doi.org/10.1016/j.proeng.2012.08.137

Mébarki, A.; Nguyen, Q. B.; Mercier, F. 2009. Structural fragments and explosions in industrial facilities. Part II: projectile trajectory and probability of impact, Journal of Loss Prevention in Process Industries 22(4): 417-425. http://dx.doi.org/10.1016/j.jlp.2009.02.005

Morinière, F. D.; Alderliesten, R. C.; Benedictus, R. 2014. Modelling of impact damage and dynamics in fibre-metal laminates - a review, International Journal of Impact Engineering 67: 27-38. http://dx.doi.org/10.1016/j.ijimpeng.2014.01.004

Oggero, A.; Darbra, R. M.; Muñoz, M.; Planas, E.; Casal, J. 2006. A survey of accidents occurring during the transport of hazardous substances by road and rail, Journal of Hazardous Materials 133(1-3): 1-7. http://dx.doi.org/10.1016/j.jhazmat.2005.05.053

Papazoglou, I. A.; Aneziris, O. N. 1999. Uncertainty quantification in the health consequences of the boiling liquid expanding vapour explosion phenomenon, Journal of Hazardous Materials 67(3): 217-235. http://dx.doi.org/10.1016/S0304-3894(99)00041-2

PHMSA. 2014. Pipeline and hazardous materials safety administration [online], [cited 18 April 2014]. Available from Internet: http://phmsa.dot.gov/hazmat/library/data-stats/ incidents

Planas, E.; Pastor, E.; Casal, J.; Bonilla, J. M. 2015. Analysis of the boiling liquid expanding vapor explosion (BLEVE) of a liquefied natural gas road tanker: the Zarzalico accident, Journal of Loss Prevention in the Process Industries 34: 127-138. http://dx.doi.org/10.1016/j.jlp.2015.01.026

Planas-Cuchi, E.; Gasulla, N.; Ventosa, A.; Casal, J. 2004. Explosion of a road tanker containing liquefied natural gas, Journal of Loss Prevention in Process Industries 17(4): 315-321. http://dx.doi.org/10.1016/j.jlp.2004.05.005

Prugh, R. W. 1994. Quantitative evaluation of fireball hazards, Process Safety Progress 13(2): 83-91. http://dx.doi.org/10.1002/prs.680130211

Pula, R.; Khan, F. I.; Veitch, B.; Amyotte. P. R. 2007. A model for estimating the probability of missile impact: Missiles 
originating from horizontal cylindrical vessels, Process Safety Progress 26(2): 129-139.

http://dx.doi.org/10.1002/prs.10178

Qiu, S.; Sacile, R.; Sallak, M.; Schön, W. 2015. On the application of valuation-based systems in the assessment of the probability bounds of hazardous material transportation accidents occurrence, Safety Science 72: 83-96. http://dx.doi.org/10.1016/j.ssci.2014.08.006

Quest Consultants. 2009. Comparative quantitative risk analysis of motor gasoline, $L P G$, and anhydrous ammonia as an automotive fuel. Prepared for Iaowa State University. Quest Consultants Inc., Norman, Oklahoma. 59 p.

Ronza, A.; Vilchez, J. A.; Casal, J. 2007. Using transportation accident databases to investigate ignition and explosion probabilities of flammable spills, Journal of Hazardous Materials 146(1-2): 106-123. http://dx.doi.org/10.1016/j.jhazmat.2006.11.057

Saat, M. R.; Werth, C. J.; Schaeffer, D.; Yoon, H.; Barkan, C. P. L. 2014. Environmental risk analysis of hazardous material rail transportation, Journal of Hazardous Materials 264: 560-569. http://dx.doi.org/10.1016/j.jhazmat.2013.10.051

Sankararaman, S.; Mahadevan, S. 2013. Separating the contributions of variability and parameter uncertainty in probability distributions, Reliability Engineering \& System Safety 112: 187-199. http://dx.doi.org/10.1016/j.ress.2012.11.024

Spoelstra, M.; Mahesh, S.; Kooi, E.; Heezen, P. 2015. Domino effects at LPG and propane storage sites in the Netherlands, Reliability Engineering \& System Safety 143: 8590. http://dx.doi.org/10.1016/j.ress.2015.06.018

Spraggings, B. H. 2010. The case for rail transportation of hazardous materials, Journal of Management and Marketing Research, 3(1): 88-95.

Sun, D.; Jiang, J.; Zhang, M.; Wang, Z. 2015. Influence of the source size on domino effect risk caused by fragments, Journal of Loss Prevention in Process Industries 35: 211223. http://dx.doi.org/10.1016/j.jlp.2015.05.005

Tauseef, S. M.; Abbasi, T.; Abbasi, S. A. 2010. Risks of fire and explosion associated with the increasing use of liquefied petroleum gas, Journal of Failure Analysis and Prevention 10(4): 322-333. http://dx.doi.org/10.1007/s11668-010-9360-9

Tewarson, A. 2002. Generation of heat and chemical compounds in fires, Section 3, in P. J. DiNenno (Ed.). SFPE handbook of fire protection engineering. $3^{\text {rd }} \mathrm{ed}$. Quincy, MA: NFPA \& SFPE, 3-87-3-161.

TNO. 2005. Tanks. Reduction of the risk of a BLEVE. TNO Report. TNO, The Hague. 3 p.
Vaidogas, E. R. 2007a. Prediction of accidental actions likely to occur on building structures. An approach based on stochastic simulation. Vilnius: Technika. 247 p. http://dx.doi.org/10.3846/1373-M

Vaidogas, E. R. 2007b. Risk oriented design of protective highway structures, The Baltic Journal of Road and Bridge Engineering 2(4): 155-163.

Vaidogas, E. R.; Juocevičius, V. 2009. Assessment of structures subjected to accidental actions using crisp and uncertain fragility functions, Journal of Civil Engineering and Management 15(1): 95-104. http://dx.doi.org/10.3846/1392-3730.2009.15.95-104

Vaidogas, E. R. 2009. On applying sparse and uncertain information to estimating the probability of failure due to rare abnormal situations, Information Technology and Control 38(2): 135-146.

Vaidogas, E. R.; Juocevičius, V. 2007. Assessing external threats to structures using limited statistical data: an approach based on data resampling, Technological and Economic Development of Economy 13(2): 170-175.

Vaidogas, E. R.; Juocevičius, V. 2008. Reliability of a timber structure exposed to fire: estimation using fragility function, Mechanika 5: 35-42.

Vaidogas, E. R.; Linkute, L. 2012. Sitting the barrier aimed at protecting roadside property from accidental fires and explosions on road: a pre-optimisation stage, The Baltic Journal of Road and Bridge Engineering 7(4): 277-287. http://dx.doi.org/10.3846/bjrbe.2012.37

Vaidogas, E. R.; Linkute, L.; Stulgys, D. 2012a. Simulationbased predicting the position of road tank explosions. Part I: data and models, Transport 27(1): 14-24. http://dx.doi.org/10.3846/16484142.2012.663732

Vaidogas, E. R.; Linkutè, L.; Stulgys, D. 2012b. Simulationbased predicting the position of road tank explosions. Part II: a case study, Transport 27(2): 118-128. http://dx.doi.org/10.3846/16484142.2012.690139

Vaidogas, E. R.; Šakènaitė, J. 2010. Protecting built property against fire disasters: multi-attribute decision making with respect to fire risk, International Journal of Strategic Property Management 14(4): 391-407. http://dx.doi.org/10.3846/ijspm.2010.29

Vaidogas, E. R.; Šakènaitè, J. 2011. Multi-attribute decisionmaking in economics of fire protection, Inzinerine Ekonomika - Engineering Economics 22(3): 262-270.

$\mathrm{Xu}$, S.; Ruan, D.; Lu, G.; Yu, T. X. 2015. Collision and rebounding of circular rings on rigid target, International Journal of Impact Engineering 79: 14-21. http://dx.doi.org/10.1016/j.ijimpeng.2014.07.005

Egidijus Rytas VAIDOGAS. PhD, Full Professor, Faculty of Civil Engineering, Vilnius Gediminas Technical University. Research interests: safety of industrial facilities, structural reliability, fire safety, safe transportation hazardous materials, decision making theories.

Lina KISEŽAUSKIENĖ. PhD, Associate Professor, Faculty of Civil Engineering, Vilnius Gediminas Technical University. Research interests: fire safety, safe transportation hazardous materials.

Ingrida GIRNIENĖ. Lecturer, Faculty of Civil Engineering, Vilnius Gediminas Technical University. Research interests: occupational safety and fire safety. 